\title{
Efficacy of a newly developed cartoon video on dry powder inhaler technique: a multicenter study
}

\author{
Thitima Sirimontakan, ${ }^{1}$ Wiparat Manuyakorn, ${ }^{1}$ Harutai Kamalaporn, ${ }^{1}$ Pornchai Wattanarungsun, ${ }^{2}$ Kuntalee Chonpaisan, ${ }^{3}$ \\ Korakot Thongkum, ${ }^{4}$ Prapasiri Singvijarn, ${ }^{5}$ Sintra Phumethum ${ }^{6}$
}

\begin{abstract}
Background: One of the factors associated with uncontrolled pediatric asthma is inadequate delivery of inhaled medication to the lungs. Incorrect inhaler technique has been reported. We developed a 2-minute cartoon video instruction aiming to improve dry powder inhaler (DPI) technique.
\end{abstract}

Objective: To assess the efficacy of video instruction in improvement of DPI technique in Thai children with asthma.

Methods: The prospective multicenter cohort study was conducted during March 2018 - February 2019. Children with asthma aged 6-15 years were recruited from the outpatient departments. Five videotapes demonstrated how the patients use DPI devices were recorded as the followings: before and after watching video ( $\mathrm{V}_{1}$ pre and $\mathrm{V}_{1}$ post), at one-month $\left(\mathrm{V}_{2}\right.$ post), at three-month $\left(\mathrm{V}_{3}\right.$ post $)$ after watching the video and at 5-month follow-up without watching the video $\left(\mathrm{V}_{4}\right.$ pre). Scoring of correct DPI steps were evaluated by two independent respiratory specialists.

Result: Of 57 patients recruited, 30 used Accuhaler ${ }^{\mathrm{rm}}$ while 27 used Easyhaler $^{\mathrm{Tm}}$. In Accuhaler ${ }^{\mathrm{rm}}$ group, the median age (range) of $10(8,11)$ year. The mean score of $\mathrm{V}_{1}$ pre, $\mathrm{V}_{1}$ post, $\mathrm{V}_{2}$ post and $\mathrm{V}_{3}$ post were $10.7,12.3,12.4$, and 12.2 out of 14 respectively. In Easyhaler ${ }^{\mathrm{T \omega}}$ group, the median age (range) of 11 (9-12) year. The mean score of $\mathrm{V}_{1}$ pre, $\mathrm{V}_{1}$ post, $\mathrm{V}_{2}$ post and $\mathrm{V}_{3}$ post were 8.6, 10.4, 11.2 and 11.4 out of 12 respectively. At the five-month follow-up, without watching video, the $\mathrm{V}_{4}$ pre score was still as high as $12.9 \pm 1.3$ in Accuhaler $^{\mathrm{Tm}}$ and $11.8 \pm 0.4$ in Easyhaler ${ }^{\mathrm{Tm}}$.

Conclusion: Our video instruction could improve Accuhaler ${ }^{\mathrm{Tm}}$ and Easyhaler ${ }^{\mathrm{Tm}}$ technique among Thai children with asthma.

Key words: pediatric asthma, dry powder inhaler, inhaler techniques, video instruction, multicenter study

\section{Citation:}

Sirimontakan, T., Manuyakorn, W., Kamalaporn, H.,

Wattanarungsun, P., Chonpaisan, K., Thongkum, K., Singvijarn, P., Phumethum, S. (2022). Efficacy of a newly developed cartoon video on dry powder inhaler technique: a multicenter study. Asian Pac J Allergy Immunol, 40(3), 217-222. https://doi.org/10.12932/ap-240719-0607

\footnotetext{
Affiliations:

${ }^{1}$ Department of Pediatrics, Faculty of Medicine, Ramathibodi hospital, Mahidol University, Bangkok, Thailand

2 Department of Pediatrics, Chaophraya Yommaraj hospital, Suphanburi, Thailand

${ }^{3}$ Department of Pediatrics, Yala hospital, Yala, Thailand

${ }^{4}$ Department of Pediatrics, Vajira Phuket hospital, Phuket, Thailand

${ }^{5}$ Department of Pediatrics, Charoenkrung Pracharak hospital, Bangkok, Thailand

${ }^{6}$ Department of Pediatrics, Prapokklao hospital, Chanthaburi, Thailand
}

Corresponding author:

Harutai Kamalaporn

270 Rama VI road, Thung Phaya Thai, Ratchathewi,

Bangkok 10400, Thailand

E-mail: Harutai.Kam@gmail.com

\section{Introduction}

Uncontrolled asthma is prevalent in children worldwide, although many pediatric asthma guidelines and effective medications have been developed. The prevalence of asthma is more increasing in affluent countries. Previous study in Thailand reported that less than half of Thai elementary school children with asthma achieved control. ${ }^{1}$

Various interventions have been established to solve this problem. One of the possible hypotheses would be that asthma medicines could not be delivered into the lungs properly. 
Several studies revealed that $14-80 \%$ of inhaler devices were used incorrectly ${ }^{2-8}$ even though these patients had been previously instructed. ${ }^{7}$ In Thailand, instructions of how to use asthma medications during outpatient department visit were scarcely delivered by physicians but given by pharmacists or nurses. Many studies regarding techniques and demonstrations to help the patients using devices in effective ways have been carried out. ${ }^{9-14}$ Most of them are instructions for the metered dose inhaler (MDI) devices. Dry powder inhaler (DPI) is recommended in children older than five years depending on their inspiratory flow and coordination. ${ }^{15}$ We created a new tool aiming to teach and remind children with asthma how to use their DPI correctly. Our 2-minute cartoon VDO is a children-friendly version emphasizing on the crucial steps to enhance lung deposition of DPI medication. The objective is to prove that this new tool can improve the DPI technique in Thai children with asthma.

\section{Methods \\ Subjects}

This study has been registered in the Thai Clinical Trials Registry (TCTR). TCTR identification number: TCTR2019 0718005. This prospective multicenter cohort study was conducted during March 2018 to February 2019. Participants were recruited from the outpatient department of $5 \mathrm{sec}-$ ondary care hospitals in different parts of Thailand; namely, Charoenkrung Pracharak hospital, Chaophraya Yommaraj hospital, Yala hospital, Vajira Phuket hospital and Prapokklao hospital. These eligible subjects were asthmatic children aged 6-18 who have been using dry powder inhaler (Accuhaler ${ }^{\mathrm{TM}}$ or Easyhaler ${ }^{\mathrm{TM}}$ ).

This study was approved by the medical ethics committee of Ramathibodhi hospital, Charoenkrung Pracharak hospital, Chaophraya Yommaraj hospital, Yala hospital, Vajira Phuket hospital and Prapokklao hospital. The written informed consents were obtained from the children or their parents.

Demographic data, level of asthma control, current medication use, dosages to determine asthma severity and the instructors who teach the patients to use DPI from each site were recorded. Patients were asked to demonstrate how they usually use DPI devices before seeing the respiratory specialists (pediatric pulmonologist or pediatric allergist) $\left(\mathrm{V}_{1}\right.$ pre). The patients were asked to watch our 2-minute cartoon video instruction by the asthma clinic coordinators. The videotapes were recorded immediately after watching our video cartoon instruction without any added instruction from the healthcare personnel ( $\mathrm{V}_{1}$ post $)$. At 1-month and 3-month follow-up, the cartoon video was seen and the patient's demonstration of how to use DPI were recorded as $\mathrm{V}_{2}$ post and ${ }_{3}$ post. At 5-month follow-up, the patients were asked to show how to use DPI without watching the video $\left(\mathrm{V}_{4}\right.$ pre $)$. The questionnaires about the satisfaction of video instruction were answered by the participants. The common available DPI devices in our 5 research sites were Easyhaler ${ }^{\mathrm{TM}}$ and Accuhaler $^{\text {TM }}$. The steps of DPI use were divided into 11 steps (total 12 scores) for Easyhaler ${ }^{\mathrm{mm}}$ and 13 steps (total 14 scores)

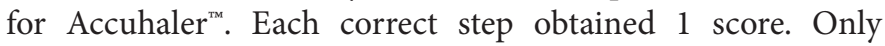
the mandatory step which was "deeply and quickly breathe through the device" obtained 2 scores. The most frequent error steps were determined. The steps were assessed and scored by two independent pediatric respiratory specialists without labeling the order of each patient's videos. The percentage of participants who correctly use of the device before and after watching video were compared at the first visit. The total inhaler technique score before watching VDO at the first visit $\left(\mathrm{V}_{1}\right.$ pre $)$, immediately after watching VDO at the first visit ( $\mathrm{V}_{1}$ post), after watching $\mathrm{VDO}$ at 1 -month ( $\mathrm{V}_{2}$ post), after watching $\mathrm{VDO}$ at 3-month follow-up ( $\mathrm{V}_{3}$ post) were compared.

During the period of study, we didn't allow any feedback from the healthcare personnel. Also both healthcare personnel and the patients have never acknowledged which steps were monitored and scored.

\section{Statistical Analysis}

Data were analyzed using SPSS (Statistical Package for the Social Sciences) for Windows. Using $V_{1}$ pre- the patients' baselines of DPI skills as a reference value, the repeated measurement ANOVA was used to compare the mean scores of $\mathrm{V}_{1}$ pre vs. $\mathrm{V}_{1}$ post (baseline vs. after watching our VDO at the first visit), $V_{1}$ pre vs. $V_{2}$ post (baseline vs. after watching VDO in asthma clinic at the 1-month follow-up) and $\mathrm{V}_{1}$ pre vs. $\mathrm{V}_{3}$ post (baseline vs. after watching VDO in asthma clinic at the 3-month follow-up).

The paired sample t-test was chosen to compare the mean of inhaler technique scores between the three-month follow-up (after watching $\mathrm{VDO} ; \mathrm{V}_{3}$ post) and the five-month follow-up (without watching $\mathrm{VDO} ; \mathrm{V}_{4}$ pre) to evaluate the maintenance of DPI skills after a 2-month period.

\section{Video Coding}

Dry powder inhaler technique for each video was evaluated by two independent respiratory specialists (pediatric allergist and pediatric pulmonologist) who were not involved in the 5 hospitals which were recruited. Also, the order of the video for each of the patients was blinded. Two coders scored the same set of 10 patients' demonstrations VDO to assess inter-rater reliability. Then, all of the videos were also coded to assess intra-rater reliability. The correction of each step were considered to be "correct" or "incorrect". Therefore the Kappa values were used to interpret the agreement. Kappa values between $0.8-1$ reflects a favorable agreement.

\section{Results}

The background characteristics were shown in Table $\mathbf{1}$. Fifty-seven participants from 5 secondary care hospitals were recruited into the study, 30 were Accuhaler ${ }^{\text {Tn }}$ users while 27 were $^{\text {Easyhaler }}{ }^{\mathrm{Tm}}$ users. The demographic data, duration of have been using the DPI medication, level of asthma control, degree of asthma severity, family income and educational level of care givers, the number of participants and the DPI instructors from each site were demonstrated in Table 1. All of the patients had been using the DPI device for over 2 months. More than half of the participants still had asthma exacerbations in the past 12 months. The DPI technique was introduced by one health care provider in majority of 
Table 1. Demographic data

\begin{tabular}{|c|c|c|}
\hline Characteristics & $\begin{array}{c}\text { Accuhaler }^{\mathrm{TM}} \\
(\mathrm{N}=\mathbf{3 0})\end{array}$ & $\begin{array}{c}\text { Easyhaler }^{\text {isc }} \\
(\mathbf{N}=27)\end{array}$ \\
\hline Age (yr) median (range) & $10(8,11)$ & $11(9,12)$ \\
\hline Duration of having been using DPI (mo) & $7(2,8)$ & $6(3,10)$ \\
\hline Male gender, N (\%) & $17(57)$ & $25(93)$ \\
\hline Exacerbation in the past 12 months, $\mathrm{N}(\%)$ & $27(60)$ & $18(56)$ \\
\hline \multicolumn{3}{|l|}{ Level of asthma control, N (\%) } \\
\hline Complete control & $10(33)$ & $10(37)$ \\
\hline Well control & $2(7)$ & $2(7)$ \\
\hline Partly control & $14(47)$ & $15(56)$ \\
\hline Uncontrol & $4(13)$ & - \\
\hline \multicolumn{3}{|l|}{ Education level of caregivers, N (\%) } \\
\hline None & $1(3)$ & 0 \\
\hline Primary school & $9(30)$ & $8(30)$ \\
\hline Secondary school & $12(40)$ & $8(30)$ \\
\hline Bachelor degree & $5(17)$ & $11(40)$ \\
\hline Higher & $3(10)$ & - \\
\hline \multicolumn{3}{|l|}{ Family income, $\mathbf{N}(\%)$} \\
\hline$<5,000 \mathrm{THB} /$ month & $2(6)$ & $1(4)$ \\
\hline 5000-10,000 THB/month & $9(30)$ & $7(26)$ \\
\hline 10,000-20,000 THB/month & $8(27)$ & $10(37)$ \\
\hline$>20,000 \mathrm{THB} / \mathrm{month}$ & $11(37)$ & $9(33)$ \\
\hline \multicolumn{3}{|l|}{ Participants from each site, N (\%) } \\
\hline Charoenkrung Pracharak hospital & $2(6)$ & - \\
\hline Chaophraya Yommaraj hospital & $5(17)$ & - \\
\hline Yala hospital & $8(27)$ & $9(33)$ \\
\hline Vajira Phuket hospital & $12(40)$ & $11(41)$ \\
\hline Prapokklao hospital & $3(10)$ & $7(26)$ \\
\hline
\end{tabular}

the participated sites except at Prapokklao hospital where 2 instructors (doctor and pharmacist) were reported. The intra-rater reliability values of the two pediatric respiratory specialists were 0.8 and 0.9 while the inter-rater reliability values were in between $0.8-1$.

\section{Evaluation of an Accuhaler ${ }^{\mathrm{mi}}$ technique}

Among 30 Accuhaler $^{\mathrm{m}}$ users, $57 \%$ were male with the median age (range) of $10(8,11)$ year. The duration of having been using this device before recruitment to the study was median (range) of $7(2,8)$ month. The least correct step $(23 \%)$ was "breathing out before inhaling the medication" as shown in Table 2. There was no statistical difference of the baseline scores $\left(\mathrm{V}_{1}\right.$ pre) between children aged 6-11 years vs. children $\geq 12$ years old (10.7 vs. 10.7). The baseline scores of children who have been using DPI devices less than 3 months vs. $\geq$ 3 months were 10.0 and 11.3 respectively. The percentages of children who perform the correct inhalation technique in each step were immediately increased after watching the 2-minute cartoon video since the first OPD visit (Table 2). In this group, the mean score of $\mathrm{V}_{1}$ pre, $\mathrm{V}_{1}$ post, $\mathrm{V}_{2}$ post and $\mathrm{V}_{3}$ post were $10.7,12.3,12.4$, and 12.2 out of 14 respectively ( $p$ $<0.01$ ) (Figure 1).

\section{Evaluation of an Easyhaler ${ }^{\mathrm{Tm}}$ technique}

In Easyhaler ${ }^{\mathrm{mm}}$ group, $93 \%$ were male with the median age (range) of $11(9,12)$ year. The duration of having been using this device before recruitment to the study was median (range) of $6(3,10)$ month. There was no statistical difference of the baseline scores $\left(\mathrm{V}_{1}\right.$ pre $)$ between children aged 6-11 years vs. children $\geq 12$ years old ( 8.9 vs. 7.9 ). The baseline scores of children who have been using DPI devices less than 3 months vs. $\geq 3$ months were 7.0 and 8.0 respectively. The "Forget to breathe out normally before inhalation" appeared to be the most common error among the Easyhaler ${ }^{\text {rox }}$ users. The percentage of children using the correct inhalation technique was increased in each step after they had watched the video instruction. (Table 3). The mean score of $\mathrm{V}_{1}$ pre, $\mathrm{V}_{1}$ post, $\mathrm{V}_{2}$ post and $\mathrm{V}_{3}$ post were 8.6, 10.4, 11.2 and 11.4 out of 12 respectively $(p<0.01)$ (Figure 2).

Table 2. Percentage of patients who can perform correct inhaler technique immediately after watching VDO

\begin{tabular}{|c|c|c|c|}
\hline \multirow{2}{*}{ Accuhaler $^{\mathrm{rm}}(\mathbf{N}=\mathbf{3 0})$} & \multicolumn{2}{|c|}{$\mathbf{N}(\%)$} & \multirow{2}{*}{$p$-value } \\
\hline & Pre (V1) & Post (V2) & \\
\hline 1. Hold the outer case in one hand & $17(57)$ & $24(80)$ & 0.05 \\
\hline 2. Place the thumb of the other hand in the thumb grip & $25(83)$ & $28(93)$ & 0.42 \\
\hline 3. Slide the outer case away from you until it clicks & $29(97)$ & $30(100)$ & 1 \\
\hline 4. Hold your Accuhaler ${ }^{\text {rm }}$ mouthpiece towards you & $19(63)$ & $28(93)$ & $<0.01$ \\
\hline 5. Slide the lever away from you until it clicks & $29(97)$ & $30(100)$ & 1 \\
\hline 6. Hold your Accuhaler ${ }^{\mathrm{rm}}$ away from your mouth & $8(27)$ & $19(63)$ & $<0.01$ \\
\hline 7. Breathe out as far as is comfortable & $7(23)$ & $12(40)$ & 0.17 \\
\hline 8. Place the mouthpiece between your lips & $30(100)$ & $30(100)$ & - \\
\hline
\end{tabular}


Table 2. (Continued)

\begin{tabular}{|c|c|c|c|}
\hline \multirow{2}{*}{ Accuhaler $^{\mathrm{mw}}(\mathbf{N}=\mathbf{3 0})$} & \multicolumn{2}{|c|}{$\mathbf{N}(\%)$} & \multirow{2}{*}{$p$-value } \\
\hline & Pre (V1) & Post (V2) & \\
\hline 9. Breathe in quickly and deeply through your Accuhaler ${ }^{\mathrm{m}}$ & $22(73)$ & $23(77)$ & 0.35 \\
\hline 10. Remove your Accuhaler ${ }^{\text {rit }}$ from your mouth & $30(100)$ & $30(100)$ & 1 \\
\hline 11. Hold your breath for 10 seconds (or as long as is comfortable) & $16(53)$ & $27(90)$ & $<0.01$ \\
\hline 12. Breathe out slowly and calmly & $22(73)$ & $29(97)$ & 0.03 \\
\hline 13. Close your Accuhaler" by sliding the outer case & $26(87)$ & $27(90)$ & 1 \\
\hline
\end{tabular}

$P$-value calculated from Chi-square

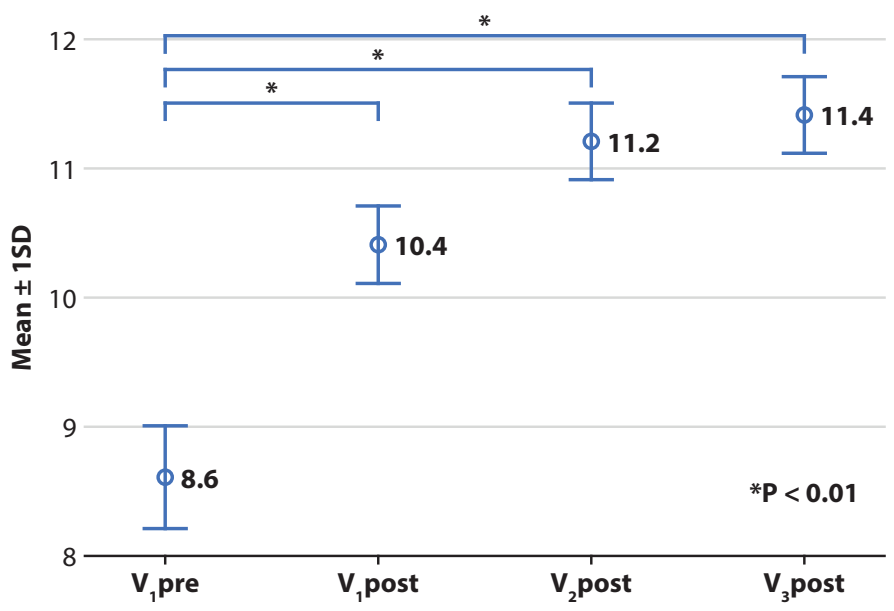

Figure 1. Comparison the total score of correct technique among the Accuhaler ${ }^{\mathrm{Tw}}$ users. Before watching VDO ( $\mathrm{V}_{1}$ pre), immediately after watching $\mathrm{VDO}$ at the first visit $\left(\mathrm{V}_{1}\right.$ post), after watching $\mathrm{VDO}$ at 1 -month ( $\mathrm{V}_{2}$ post), after watching VDO at 3- month follow-up ( $\mathrm{V}_{3}$ post $)$.

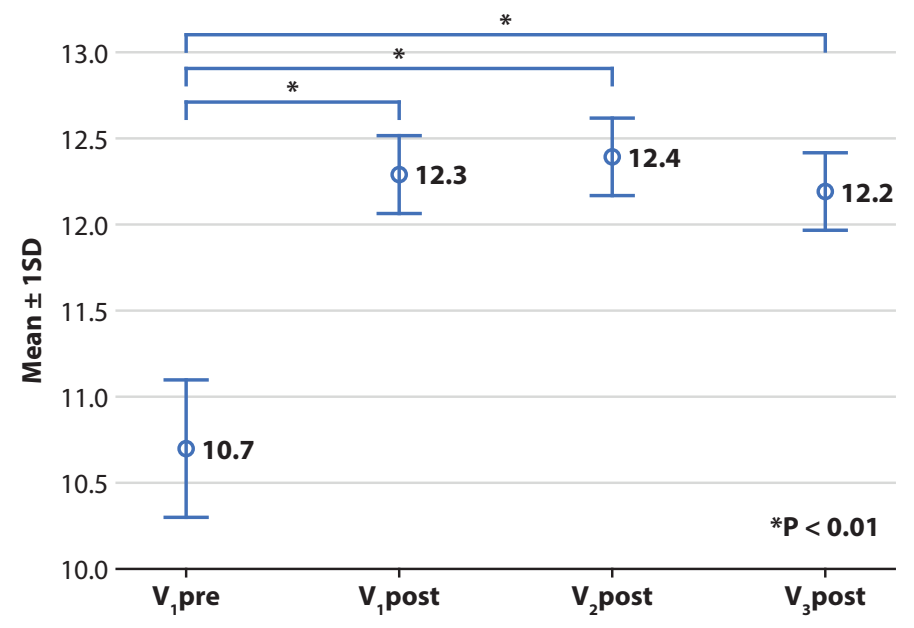

Figure 2. Comparison the total score of correct technique among the Easyhaler ${ }^{\mathrm{Tm}}$ users. Before watching VDO ( $\left.\mathrm{V}_{1} \mathrm{pre}\right)$, immediately after watching $\mathrm{VDO}$ at the first visit $\left(\mathrm{V}_{1}\right.$ post), after watching $\mathrm{VDO}$ at 1 -month $\left(\mathrm{V}_{2}\right.$ post), after watching VDO at 3- month follow-up ( $\mathrm{V}_{3}$ post).

Table 3. Percentage of patients who can perform correct inhaler technique immediately after watching VDO

\begin{tabular}{|c|c|c|c|}
\hline \multirow{2}{*}{ Easyhaler $^{\mathrm{nt}}(\mathbf{N}=27)$} & \multicolumn{2}{|c|}{$\mathbf{N}(\%)$} & \multirow{2}{*}{$p$-value } \\
\hline & Pre (V1) & Post (V2) & \\
\hline 1.Remove the dust cap & $27(100)$ & $27(100)$ & - \\
\hline 2. Shake the Easyhaler ${ }^{\text {tax }}$ vigorously up and down three to five times & $16(59)$ & $24(89)$ & 0.01 \\
\hline 3. After shaking hold the Easyhaler ${ }^{\mathrm{Tx}}$ in the upright position & $13(48)$ & $22(82)$ & 0.01 \\
\hline $\begin{array}{l}\text { 4. Press the Easyhaler }{ }^{\text {tx }} \text { once between your finger and thumb until } \\
\text { your hear a click }\end{array}$ & $26(96)$ & $26(96)$ & 1 \\
\hline 5. After clicking hold the Easyhaler ${ }^{\mathrm{Tx}}$ in the upright position & $12(44)$ & $20(74)$ & 0.03 \\
\hline 6. Breathe out normally (but not into the Easyhaler ${ }^{\mathrm{Tt}}$ ) & $7(26)$ & $19(70)$ & $<0.01$ \\
\hline $\begin{array}{l}\text { 7. Place the mouthpiece in your mouth between your teeth and seal } \\
\text { your lips tightly around it }\end{array}$ & $24(89)$ & $25(93)$ & 1 \\
\hline 8. Take a strong and deep breath through the Easyhaler ${ }^{\mathrm{ra}}$ & $18(67)$ & $23(85)$ & 0.11 \\
\hline 9. Remove the Easyhaler ${ }^{\mathrm{rm}}$ from your mouth & $27(100)$ & $27(100)$ & - \\
\hline 10. Hold your breath for at least 5 seconds, then breathe normally & $20(74)$ & $23(85)$ & 0.31 \\
\hline 11. Put the dust cap back on the mouthpiece & $22(82)$ & $23(85)$ & 1 \\
\hline
\end{tabular}

$P$-value calculated from Chi-square 


\section{Patients' satisfaction}

Seventy percent of patients reported that they recognized all steps from the VDO right after watching it. All of the DPI users admitted that the VDO is useful. The preference of teaching method from VDO instruction more than from the health care providers were observed in both DPI devices $(20 \%$ vs $10 \%$ in Accuhaler $^{\mathrm{TN}}$ and $33 \%$ vs $7 \%$ in Easyhaler ${ }^{\mathrm{TN}}$ group).

Sixty-three percent (19 of 30) patients in the Accuhaler ${ }^{\mathrm{Tm}}$ group and 60\% (16 of 27) patients in an Easyhaler ${ }^{\mathrm{Tm}}$ group preferred the teaching methods from both VDO and the healthcare providers.

\section{At 5-month follow-up}

Ten of 30 among Accuhaler ${ }^{\mathrm{Tw}}$ users and 13 of 27 in Easyhaler $^{\text {Ts }}$ users were assessed at the 5-month follow-up. Without watching video the total score was still high as $12.9( \pm 1.3)$ out of 14 in Accuhaler $^{\mathrm{Tm}}$ and $11.8( \pm 0.4)$ out of 12 in EasyhalerTM (Table 4).

Table 4. At 3-month $\left(\mathrm{V}_{3}\right.$ post $)$ and 5-month $\left(\mathrm{V}_{4}\right.$ pre) followup: the total score

\begin{tabular}{|l|c|c|c|}
\hline & $\mathbf{V}_{3}$ post & $\mathbf{V}_{4}$ pre & $p$-value \\
\hline Accuhaler $^{\mathrm{mw}}, \mathrm{N}=10$ & $11.5( \pm 0.9)$ & $12.9( \pm 1.3)$ & 0.05 \\
\hline Easyhaler $^{\mathrm{mu}}, \mathrm{N}=13$ & $11.5( \pm 0.8)$ & $11.8( \pm 0.4)$ & 0.31 \\
\hline
\end{tabular}

$p$-value calculated from paired sample t-test

\section{Discussion}

There are many video instructions of how to use inhaler devices in a human version exist therefore we would like to create something unique. Our target population is Thai children between the ages of 5-18 years. We presumed that the cartoon version may better draw their attention. The characters in our cartoon video are a boy and a girl of which represented the target patients aimed to make it be more user-friendly version. It is precise and short within 2 minutes emphasizing on the mandatory steps of DPI techniques. We hope that children won't get bored if they have to watch it repeatedly.

Our participants' median age was 10-11 years old which were mature enough to use DPI as per the recommendation. They have been using asthma medication in a form of DPI for at least 2 months' time. There were only 4 patients in Easyhaler $^{\mathrm{TM}}$ group and 1 patient in Accuhaler ${ }^{\mathrm{Tm}}$ group who could perform the inhaler technique correctly in all steps before watching the video instruction.

In terms of drug deposition in the lungs, only one-fourth of patients clear their airways by breathing out before inhaling the DPI medication. Approximately $67-73 \%$ of patients breathed in deeply and quickly as per a mandatory step of using DPI. Fifty - three percent of Accuhaler ${ }^{\mathrm{rm}}$ users and 74\% of Easyhaler $^{\mathrm{TM}}$ users could hold their breaths as long as 5-10 seconds as is the pharmaceutical company recommended. To promote lung deposition of asthma medication in DPI device, the patients should perform these 3 steps correctly. After watching our VDO, we demonstrated the improvement in these steps.
In terms of medical regulation, the Easyhaler ${ }^{\mathrm{Tm}}$ should be shaken vigorously and kept in an upright position to prevent the spills but only $60 \%$ of our participants were aware of this. It was recommended not to exhale into the mouthpiece that may increase the damp causing the clump and occlusion within the device. Only 27\% of Accuhaler $^{\mathrm{Tm}}$ users hold the device away from their mouth in order not to exhale into the device. After watching our video, the percentage of the correct users in these steps was increased.

Our study discovered that the most common error step of Accuhaler $^{\text {TM }}$ users was the patient did not breathe out to clear the lungs before inhaling the medication. The proportion of children performing this step correctly were improved from $23 \%$ to $40 \%$ but it remained low. Although this is not a crucial step as much as breathing in deeply and quickly, exhalation to the functional residual capacity (FRC) could be helpful in promoting the bigger breath than the usual tidal volume when inhaling the medication. This was different from the previous studies $^{8,16}$ that the patients exhaled but too close to the DPI mouthpiece which may increase the clump.

At 1 and 3-month follow-up, repeated ANOVA revealed that the total scores were higher than the first visit $\left(\mathrm{V}_{1}\right.$ pre $)$ in both device as shown in the Figure 1 and 2. However, it was doubtful whether these higher scores derived from the recent memory right after watching our cartoon video. Therefore, we asked the patients to demonstrated how to use DPI at the 5-month follow up without watching video. We observed that $\mathrm{V}_{4}$ pre total scores were not differ from the $\mathrm{V}_{3}$ post score. Moreover, the patients DPI technique from $\mathrm{V}_{1}$ pre to $\mathrm{V}_{4}$ pre had been improved and maintained. In addition, an increment in the percentages of children who achieved the correct inhalation technique in each step was observed.

Previous studies demonstrated that the video instructions were useful in promoting correct inhaler techniques. ${ }^{10-14}$ None of them us the video instruction for children using DPI which were Accuhaler $^{\text {Ti }}$ and Easyhaler $^{\text {Tm }}$ like ours. Carpenter DM et al. ${ }^{12}$ used the video to teach the metered dose inhaler technique and Koichiro $\mathrm{T}$ et al. ${ }^{17}$ provided the DVD for 12 inhaler types in adult patients.

Correct device technique is considered essential for sufficient delivery of inhaled medication but it is only one part of the factors to reach asthma control. Previous study has shown the outcome of correct techniques without any comparison in asthma control level. ${ }^{11}$ Having asthma control requires multifactorial efforts such as the proper medication used, medication adherence, environmental control, good monitoring and correct action during exacerbations. Therefore, we did not compare asthma control before and after watching our VDO.

Our new tool is feasible in a form of QR code which could be easily accessed from smart phones, tablets, or computer. We hope that children will not get bored if they have to watch it repeatedly to assure their correct DPI techniques. The VDO is useful in its feasibility but could not replace the human communication. Approximately $60 \%$ of patients still preferred both teaching methods. In the real-life practice, we recommend that the healthcare providers should discuss the common pitfalls with the individual patient. 
Using our video along with human instruction may help the children with asthma to use the DPI devices properly especially in the limited resource hospitals. The patient can watch it repeatedly as much as they want to remind the proper technique.

\section{Conclusion}

Our newly developed 2-minutes cartoon video instruction could improve Easyhaler ${ }^{\mathrm{TM}}$ and Accuhaler ${ }^{\mathrm{TM}}$ technique among Thai children with asthma. Our cartoon video is children friendly, emphasizing on the essential steps aimed to improve lung deposition and also drug maintenance.

\section{Acknowledgement}

The authors would like to thank all the patients who took part in this study. We appreciate the support by Faculty of Medicine, Ramathibodi Hospital's research fund (grant No. RF 61047) and there is no conflict of interest.

\section{Conflict of interest}

All authors have no conflict of interest.

\section{Financial support}

A research grant from Faculty of Medicine, Ramathibodi hospital, Mahidol University, Bangkok, Thailand

\section{References}

1. Wanlapakorn N, Sritippayawan S, Deerojanawong J. Prevalence of asthma, level of control and factors associated with asthma control in Thai elementary school students in Bangkok. Asian Pac J Allergy Immunol. 2014;32(4):287-92.

2. Pedersen S, Frost L, Arnfred T. Errors in inhalation technique and efficiency in inhaler use in asthmatic children. Allergy. 1986;41(2): 118-24.

3. Goren A, Noviski N, Avital A, Maayan C, Stahl E, Godfrey S, et al. Assessment of the ability of young children to use a powder inhaler device (Turbuhaler). Pediatr Pulmonol. 1994;18(2):77-80.
4. Boccuti L, Celano M, Geller RJ, Phillips KM. Development of a scale to measure children's metered-dose inhaler and spacer technique. Ann Allergy Asthma Immunol. 1996;77(3):217-21.

5. Larsen JS, Hahn M, Ekholm B, Wick KA. Evaluation of conventional press-and-breathe metered-dose inhaler technique in 501 patients. J Asthma. 1994;31(3):193-9.

6. Capanoglu M, Dibek Misirlioglu E, Toyran M, Civelek E, Kocabas CN. Evaluation of inhaler technique, adherence to therapy and their effect on disease control among children with asthma using metered dose or dry powder inhalers. J Asthma. 2015;52(8):838-45.

7. Kamps AW, van Ewijk B, Roorda RJ, Brand PL. Poor inhalation technique, even after inhalation instructions, in children with asthma. Pediatr Pulmonol. 2000;29(1):39-42.

8. Hagmolen of ten Have W, van de Berg NJ, Bindels PJ, van Aalderen WM, van der Palen J. Assessment of inhalation technique in children in general practice: increased risk of incorrect performance with new device. J Asthma. 2008;45(1):67-71

9. Axtell S, Haines S, Fairclough J. Effectiveness of Various Methods of Teaching Proper Inhaler Technique. J Pharm Pract. 2017;30(2):195-201.

10. Arumugom A, Chandrasekaran V. A Randomized Comparison between Video Demonstration and Verbal Instruction in Improving Rota Haler Technique in Children with Persistent Asthma: A Pilot Study. J Clin Diagn Res. 2017;11(6): SC05-7.

11. Shaw N, Le Souëf P, Turkovic L, McCahon L, Kicic A, Sly PD, et al. Pressurised metered dose inhaler-spacer technique in young children improves with video instruction. Eur J Pediatr. 2016;175(7):1007-12.

12. Carpenter DM, Lee C, Blalock SJ, Weaver M, Reuland D, Coyne-Beasley $\mathrm{T}$, et al. Using videos to teach children inhaler technique: a pilot randomized controlled trial. J Asthma. 2015;52(1):81-7.

13. Shah RF, Gupta RM. Video instruction is more effective than written instruction in improving inhaler technique. Pulm Pharmacol Ther. 2017;46:16-19.

14. Takita K, Kondo R, Horiguchi T. Effectiveness of training patients using DVD in the accurate use of inhalers for the treatment of bronchial asthma. Allergol Int. 2017;66(4):545-9.

15. National Institute for Health and Care Excellent [Internet]. London NICE; c2019 [cited 2019 Jul 18]. Inhaler devices for routine treatment of chronic asthma in older children (aged 5-15 years); [about 2 screens]. Available from https://www.nice.org.uk/guidance/ta38

16. Leath B, Ayala GX, Gillette C, Williams D, Davis S, Tudor G, Yeatts K, Washington D. Provider demonstration and assessment of child device technique during pediatric asthma visits. Pediatrics. 2011;127(4):642-8.

17. Kamps AW, Brand PL, Roorda RJ. Determinants of correct inhalation technique in children attending a hospital-based asthma clinic. Acta Paediatr. 2002;91(2):159-63. 